\title{
MODELOS SEMIÓTICOS NO TRABALHO HISTORIOGRÁFICO COM OS QUADRINHOS: QUESTÕES TEÓRICO-METODOLÓGICAS
}

\author{
Lucas Suzigan Nachtigall ${ }^{1}$
}

\begin{abstract}
RESUMO: O presente artigo tem por objetivo apontar questões teórico-metodológicas para a abordagem de quadrinhos como fonte no trabalho historiográfico. Essas questões têm como eixo central ressaltar algumas preocupações necessárias com as especificidades técnicas relacionadas ao trabalho com a arte sequencial. Essas questões são voltadas, em especial, mas não limitadamente, para os trabalhos em história social. Em um segundo momento, o artigo visa também a abordagem de perspectivas semióticas no tratamento dessa fonte para o trabalho historiográfico, dentro das preocupações apresentadas para o estudo da sequenciação. Por fim, serão apresentados alguns trabalhos relevantes da aplicação de análises semióticas dos quadrinhos no trabalho historiográfico.
\end{abstract}

PALAVRAS-CHAVE: histórias em quadrinhos; historiografia; semiótica.

\section{SEMIOTIC MODELS IN HISTORIOGRAPHIC WORK WITH COMICS: THEORETICAL-METHODOLOGICAL ISSUES}

\begin{abstract}
The present article aims to point theoretical-methodological questions related to the approach of comics as a source in the historiographic work. These issues have as central axis to highlight some needed concerns with the technical specificities related to working with sequential art. These issues are addressed, in particular, but not limited to, work in social history. Secondly, the article also aims to approach semiotic perspectives in the treatment of this source for the historiographic work, within the concerns presented for the study of sequencing. Finally, we will present some relevant works of the application of semiotic analysis of comics in the historiographic work.
\end{abstract}

KEYWORDS: comics; historiography; semiotic.

\section{MODELOS SEMIÓTICOS EN EL TRABAJO HISTORIOGRÁFICO CON LOS CUADRINOS: CUESTIONES TEÓRICO-METODOLÓGICAS}

RESUMEN: El presente artículo tiene por objectivo apuntar cuestiones teóricometodológicas para el abordaje de los cuadriños como fuente en el trabajo historiográfico. Estas cuestiones tienen como eje central resaltar algunas preocupaciones necesarias con las especificidades técnicas relacionadas al trabajo con la arte secuencial. Estas cuestiones se dirigen, en particular, pero no limitadamente, a los trabajos en historia social. En un segundo momento, el artículo apunta también la abordaje de perspectivas semióticas en el tratamiento de esa fuente para el trabajo historiográfico, dentro de las preocupaciones presentadas para el estudio de la secuenciación. Por último, se presentarán algunos trabajos relevantes de la aplicación de análisis semióticos de los cuadriños en el trabajo historiográfico.

PALABRAS CLAVE: historias en cuadriños; la historiografía; la semiótica.

\footnotetext{
${ }^{1}$ Mestre em História pela Universidade Estadual Paulista Júlio de Mesquita Filho (UNESP/Assis).
} 


\section{INTRODUÇÃO}

As histórias em quadrinhos, também conhecidas como banda desenhada em Portugal, são um gênero narrativo que incorpora os elementos da imagem desenhada com o texto escrito para contar uma história. Subgênero da arte sequencial, que utiliza uma sequência de imagens de forma a subentender uma percepção de movimento para transmitir uma mensagem, os quadrinhos se tornaram uma mídia² muito popular no século XX, com grande difusão e vendagem, chegando a influenciar a disseminação de determinadas ideologias ${ }^{3}$. Em diferentes editoras, as histórias em quadrinhos existem em vários gêneros, formatos, estilos, publicados por todo o mundo em diferentes editoras.

Apesar de ser difícil, e um tanto controverso, definir o seu início ${ }^{4}$, teorizações sobre o gênero da arte sequencial já eram feitas desde a primeira metade do século XIX ${ }^{5}$. Desde então, inúmeros trabalhos têm sido feitos com a preocupação de compreender e explicar o gênero quadrinesco. Desde artigos breves a longas obras, os trabalhos abordando os quadrinhos podem ser encontrados em vários campos do conhecimento humanístico, como, por exemplo, na historiografia, sociologia, filosofia, literatura e, especialmente, no campo da semiótica, onde os quadrinhos encontram trabalhos de grande relevância. Quadrinhos têm sido utilizados como objeto de estudo e fontes para as mais diferentes abordagens, ressaltando a relevância de seu estudo e a pertinência de sua abordagem para a compreensão das realidades da sociedade dos séculos XX e XXI.

Esse artigo abordará alguns problemas teórico-metodológicos concernentes ao tratamento dos quadrinhos como objeto e fonte na historiografia. Paralelamente, algumas obras serão problematizadas dentro desse recorte, de forma a também oferecer alguns referenciais para o trabalho com os quadrinhos na historiografia, que apresenta uma lacuna de

\footnotetext{
${ }^{2}$ Utilizo, aqui, a definição de mídia do dicionário Michaelis "Mídia: mí·di·a sf. 1 Comum. Toda estrutura de difusão de informações, notícias, mensagens e entretenimento que estabelece um canal intermediário de comunicação não pessoal, de comunicação de massa, utilizando-se de vários meios, entre eles jornais, revistas, rádio, televisão, cinema, mala direta, outdoors, informativos, telefone, internet etc." Disponível em: http://michaelis.uol.com.br/moderno-portugues/busca/portugues-brasileiro/m\%C3\%ADdia/.

${ }^{3}$ É possível lembrar, por exemplo, a criação do Capitão América em 1940-1941 como uma ferramenta de propaganda americana na Segunda Guerra Mundial, mesmo antes da entrada do país no conflito.

${ }^{4}$ Alguns autores vão considerar, por exemplo, os trabalhos de Rodolphe Topffer no fim da década de 1820 (GROENSTEEN, 2015, p. 9) como o precursor dos quadrinhos, enquanto outros vão considerar outros artistas, como o italiano radicado brasileiro Angelo Agostini em 1861 (GOIDA, 2011, p. 23) ou Richard F. Outcault em 1895 com sua tirinha "The Yellow Kid" como os reais precursores.

5 Thierry Groensteen aponta, por exemplo, as teorizações feitas por Rudophe Topffer após suas primeiras publicações como um princípio das teorizações a respeito do gênero nascente (GROENSTEEN, 2015, p. 9).
}

Fronteiras: Revista de História | Dourados, MS | v. 20 | n. 36 | p. 122-136 | Jul. / Dez. 2018 
trabalhos que façam essa síntese. Dadas as devidas adaptações, parte do conteúdo poderia ser desdobrado e considerado para o trabalho em outras áreas das ciências humanas, como por exemplo, as ciências sociais, crítica da arte e literária.

O presente artigo será dividido em três partes. Na primeira, parte, serão levantadas algumas questões pertinentes a esses problemas teórico-metodológicos, apontando alguns trabalhos historiográficos recentes relacionados aos quadrinhos. Na segunda parte, algumas alternativas a esses problemas serão apresentadas a partir de perspectivas semióticas e técnicas. E, por fim, a terceira parte vai apresentar alguns trabalhos referenciais para o uso da semiótica no estudo historiográfico dos quadrinhos.

\section{PARTE 1 \\ O TRABALHO HISTORIOGRÁFICO COM OS QUADRINHOS: QUESTÕES TEÓRICO-METODOLÓGICAS}

Como já foi dito anteriormente, as abordagens feitas dos quadrinhos nas ciências humanas são muito plurais, bem como suas preocupações e arcabouços teóricometodológicos. Há trabalhos com enfoque voltado para a área de ensino (Cf. BARI, 2012) (muito comuns trabalhos sobre o uso dos quadrinhos como ferramenta pedagógica), literária (Cf. BITAZI, 2016), filosófica (Cf. SIQUEIRA, 2012), sociológica (Cf. CHINEN, 2013), e até mesmo geográfica (Cf. MENDONÇA, 2016) e psicológica (Cf. BRAGA JR., PERRUSI, 2013), entre outras diversas, estando limitadas apenas à problemática abordada.

Porém, na maioria das abordagens dos quadrinhos feitas nas ciências humanas, algumas questões teórico-metodológicas são encontradas correntemente, relacionadas às especificidades da fonte quadrinesca. Muitos trabalhos, ao analisarem a mensagem veiculada por determinado quadrinho, acabam não tomando a devida preocupação com a forma da mensagem, mas apenas ao seu conteúdo. E essa não preocupação muitas vezes precariza as abordagens dessa mensagem, limitando-a apenas aos seus aspectos conteudísticos em detrimento dos formais.

Com relação às publicações acadêmicas relacionadas ao estudo das histórias em quadrinhos no Brasil, merece destaque a Nona Arte: Revista Brasileira de Pesquisas em Histórias em Quadrinhos, editada pelo Observatório de Histórias em Quadrinhos do ECAUSP. Essa revista, interdisciplinar, reúne artigos abordando o gênero quadrinesco dentro dos diversos campos das ciências humanas. Nesses artigos, bem como em outros, disponibilizados 
em outras revistas acadêmicas (Cf. por ex. GONÇALVES, 2008), essas questões metodológicas relativas ao tratamento da fonte podem ser facilmente percebidas.

Quanto à historiografia dos quadrinhos, podem-se destacar os trabalhos de Fábio Vieira Guerra $(2011 ; 2015)$, dois trabalhos extremamente relevantes, em que o autor traça um panorama bastante abrangente dos quadrinhos da editora Marvel entre os anos de 1961-1981 (Mestrado) e 1980-2015 (Doutorado), num trabalho de referência para o estudo dos quadrinhos de super-heróis, bem como outros quadrinhos em menor escala, nesse período.

\section{PREOCUPAÇÃO COM AS ESPECIFICIDADES DA FONTE}

As histórias em quadrinhos são uma mídia cujo estudo é, como as demais, bastante particular. Como subgênero da arte sequencial (conhecida como a nona arte), ela utiliza a justaposição de imagens que correspondam a uma determinada lógica ${ }^{6}$ para, em uma colaboração subentendida, ativa e intuitiva por parte do leitor, veicular uma narrativa. E, nesse processo de veiculação dessa narrativa, ela utiliza mecanismos distintos de outras mídias, merecendo uma atenção mais detida quanto a esses aspectos. Dessa forma, pode-se considerar que a fonte quadrinesca tem especificidades em vários níveis, cuja atenção pode trazer elementos que aprofundem e enriqueçam a análise intelectual da mesma. Aqui serão abordadas questões relacionadas ao suporte material, materiais, narrativas e ideológicas, mas considera-se que outras questões, como a linguística, possam ser observadas em diferentes abordagens teórico-metodológicas.

\section{PREOCUPAÇÃO COM O SUPORTE MATERIAL}

O quadrinho, como já dito algumas vezes, é uma mídia, entendida aqui como o tipo de suporte material para a difusão de uma mensagem, distinta. Usa mecanismos distintos, por exemplo, da literatura ou do cinema, para veicular sua narrativa. O processo de sequenciação torna a representação do movimento um processo que faz da leitura um ato de percepção estética e esforço intelectual (EISNER, 1989) que depende, ao mesmo tempo, de uma profunda colaboração implícita por parte do leitor e da existência de um código de signos

\footnotetext{
${ }^{6}$ Chamada por Thierry Groensteen de solidariedade icônica (GROENSTEEN, 2015, p. 27-28)

Fronteiras: Revista de História | Dourados, MS |v. 20 | n. 36 | p. 122-136 | Jul. / Dez. 2018
} 
visuais comuns ao a ele e ao(s) criador(es).

Os elementos estéticos presentes na narrativa quadrinesca, como pode ser facilmente deduzido, devem ter uma atenção central em qualquer estudo sobre uma obra em quadrinhos. Elementos como anatomia, o uso das cores, o enquadramento devem guiar a análise da obra, dado sua centralidade no processo de significação da narrativa. Ao mesmo tempo, os elementos estruturais da história em quadrinhos, como balões, requadros, hiperquadros, calhas, são elementos que, em sua articulação, fornecem suporte material para o processo se sequenciação, e podem ser compreendidos a partir de seus usos, encadeamentos e oposições, de forma a influir na codificação, decodificação e significação da mensagem.

Ou seja, a preocupação com os aspectos técnicos da obra, bem como a análise estética da mesma são essenciais para se compreender com mais profundidade o processo de veiculação da mensagem do quadrinho em questão, merecendo uma atenção mais detida por parte do estudioso. E essa questão terá prioridade nesse artigo, em especial na segunda parte.

\section{QUESTÕES MATERIAIS}

Relacionadas ao campo anterior, ressalta-se também a importância da atenção às questões materiais relativas ao quadrinho como, por exemplo, aquelas ligadas ao processo criativo $^{7}$ e produtivo ${ }^{8}$.

Essas preocupações giram muitas vezes em torno do campo socioeconômico, tendo relevância maior para pesquisas que envolvam esses aspectos. Dentre elas, podemos destacar questões de cunho humano relacionadas ao processo criativo, como aqueles relacionados aos desenhistas, roteiristas e editores; aquelas preocupações relacionadas aos aspectos técnicos e tecnológicos do processo produtivo, como processo de desenho propriamente dito, o avanço das técnicas artísticas e das tecnologias envolvidas na criação dos quadrinhos e sua subsequente impressão; e aquelas preocupações ligadas aos aspectos econômicos, como a distribuição, vendas dos quadrinhos, a constituição de mercados para as obras em questão.

Essas questões são muito bem discutidas, por exemplo, nos trabalhos de Moacy Cirne (1972; 1973; 1975), onde o autor aborda a criação do mercado editorial de quadrinhos no

\footnotetext{
${ }^{7}$ Que perpassa desde a concepção do quadrinho (subjetiva) até a formulação do roteiro, negociações editoriais, primeiros rascunhos, e todo o processo que antecede a produção propriamente dita do quadrinho.

${ }^{8}$ Relativa à produção do quadrinho em si, do roteiro e storyboards até o desenho, coloração, arte final, bem como o processo de impressão e distribuição.
}

Fronteiras: Revista de História | Dourados, MS | v. 20 | n. 36 | p. 122-136 | Jul. / Dez. 2018 
Brasil e a formação artística dos quadrinistas brasileiros (como, por exemplo, Ziraldo e Maurício de Souza); de Will Eisner (1989), onde o autor trabalha todo o processo de desenho e de impressão ${ }^{9}$; e de Anselmo Gimenez Mendo (2008), que centra na questão da influência digital no processo criativo dos quadrinhos, inclusive problematizando o surgimento de novos gêneros de arte sequencial, híbridos de quadrinhos, animações e internet.

Embora muitas abordagens e pesquisas possam facilmente dispensar a preocupação com relação a essas questões, muitos trabalhos se beneficiariam com a percepção dessa especificidade do processo criativo dos quadrinhos.

\section{QUESTÕES NARRATIVAS}

Como já apontado anteriormente, as questões narrativas são abordadas com mais atenção e profundidade nos estudos sobre os quadrinhos, requerendo menor detalhamento aqui. Há, entre os trabalhos sobre esse tipo de objeto, abordagens a respeito da representação de determinado aspecto, temática ou objeto nas histórias, ou até de construção e desenvolvimento de personagens e enredos nas narrativas quadrinescas, entre outras.

Uma vez que a grande maioria dos trabalhos acadêmicos relativos aos quadrinhos tem como preocupação central o estudo da narrativa quadrinesca, tornam-se desnecessárias problematizações mais detalhadas a respeito desse tópico.

\section{QUESTÕES IDEOLÓGICAS}

Por fim, é relevante ressaltar às questões ideológicas recorrentes ao processo criativo dos quadrinhos. Ligadas, por um lado, à mensagem veiculada pelos quadrinhos e, por outro, ao contexto social que os produziu, as ideologias ${ }^{10}$ são um aspecto importante para se compreender essa dimensão. Como produções artísticas de uma sociedade de massas, os quadrinhos veiculam em si e ao mesmo tempo difundem as estruturas ideológicas de uma determinada sociedade, sendo uma ferramenta útil para a compreensão dessas estruturas.

\footnotetext{
${ }^{9}$ As edições mais recentes do livro, inclusive, problematizam o avanço das técnicas de desenho com a chegada da Era Digital.

${ }^{10}$ Utilizo, aqui, o conceito de ideologia de Althusser, como trabalhado por Georges Duby em seu texto "História social e ideologias das sociedades", presente no livro organizado por Jacques Le Goff e Pierre Nora intitulado História: Novos Problemas, publicado no Brasil pela F. Alves, em 1976.
} 
Alguma atenção a essa perspectiva será dada na terceira parte, onde serão discutidos os trabalhos de Moacy Cirne e Umberto Eco sobre quadrinhos, articulando o estudo semiótico dos quadrinhos com perspectivas da história social.

\section{ALÉM DA ANÁLISE DA IMAGEM: SEQUENCIAÇÃO}

Como demonstrado anteriormente, no tratamento das histórias em quadrinhos, bem como das demais artes sequenciais, como fonte para o trabalho historiográfico, diversas preocupações, se devidamente tomadas, podem enriquecer a análise da fonte. Será ressaltado, aqui, um desses aspectos, que é a análise da sequenciação como parte do processo de análise estética da imagem, importante para se entender o processo de codificação e decodificação da narrativa quadrinesca, sendo uma etapa essencial para a análise da estética dos quadrinhos, ao mesmo tempo em que serão apresentados alguns referenciais teórico-metodológicos úteis para o trabalho com os quadrinhos.

Um referencial interessante para a discussão acerca do elemento sequencial como recurso narrativo, por exemplo, é o livro Quadrinhos e Arte Sequencial, de Will Eisner (1989). Publicado originalmente em 1985, quando os quadrinhos estavam em sua transição da chamada Era de Bronze dos Quadrinhos (Bronze Age of the Comics) para a Era Moderna dos Quadrinhos (Modern Age of the Comics), teve sua primeira edição brasileira publicada pela Martins Fontes em 1989, estando atualmente em sua quarta edição, revista e atualizada, publicada em 2010. Nele, o autor, quadrinista conhecido por diversos trabalhos, como as histórias do detetive Spirit, lançado entre as décadas de 40 e 50 e, na década de 70, pela popularização do conceito de graphic novel em seu trabalho A Contract with God, faz um estudo detido em torno do processo criativo, técnico e estrutural dos quadrinhos, abordando desde questões como os usos dos balões, do enquadramento, a significação em torno da anatomia e da construção da sequenciação para o estabelecimento de uma noção linear de tempo na narrativa até questões técnicas como o processo de roteirização, de desenho, colorização, acabamento e impressão. A edição mais recente foi ampliada para abordar também os reflexos do avanço digital na produção quadrinesca.

Nesse trabalho, Einsner discute, especialmente nos primeiros capítulos, a noção da arte sequencial como uma forma própria de leitura, constituída a partir da sobreposição entre 
imagem e palavra, mesclando de forma singular suas regências e particularizando seu processo de criação e interpretação. E, a partir dessa discussão, ele problematiza a estruturação criativa dos quadrinhos, cuja leitura, embora em muitos aspectos similar à literária, apresenta distinções, uma vez que, na sequenciação imagética do quadrinho, o próprio texto é lido como uma imagem em um processo não-linear.

E, a partir disso, Eisner aborda a noção e a representação do tempo nos quadrinhos, que muitas vezes é apreendida de forma espontânea e intuitiva pelos leitores. Abordando de forma bastante técnica os procedimentos utilizados para o cadenciamento do tempo nos quadrinhos, como o enquadramento da fala e o uso intencional do requadro (a "margem" do quadrinho), Eisner problematiza o processo de codificação do tempo por meio da sequenciação de uma forma bastante abrangente, donde argumenta que "uma vez estabelecido e disposto na sequência, o quadrinho torna-se o critério por meio do qual se julga a ilusão do tempo." (1989, p 28).

Embora se trate de uma obra de teor mais técnico, utilizando vasta iconografia para ilustrar seus questionamentos, muitos deles retirados de suas próprias obras, o livro "História em quadrinhos e arte sequencial" consiste certamente um material de referência obrigatório para o trabalho intelectual que pretende preocupar-se quanto a essas questões relacionadas ao suporte material do quadrinho enquanto fonte para o trabalho científico na área das ciências humanas.

\section{PROPOSTAS SEMIÓTICAS PARA A ANÁLISE DA ARTE SEQUENCIAL}

Ao mesmo tempo, é importante ressaltar as possibilidades do uso de modelos semióticos para o enriquecimento das análises feitas em estudos que utilizem artes sequenciais como fontes. Esses modelos (ou sistemas, como é o caso de Groensteen; v. abaixo) trazem discussões e referenciais que permitem articular teoricamente os elementos estéticos constituintes dos quadrinhos (como a margem, o requadro, a calha, o hiperquadro, as pranchas) e, assim, aprofundar a compreensão do conjunto da obra.

Ao longo do século XX diversos trabalhos semióticos, teorias e sistemas foram formulados para o estudo das histórias em quadrinhos, desde Rudophe Töpffer em seu Essai de Physiognomonie, de 1845, onde os primeiros estudos teóricos sobre os quadrinhos foram feitos, até os trabalhos de Guy Gauthier em seu Vingt leçons sur l'image et le sens (Cf. 
GAUTHIER, 1982.), onde propunha uma desconstrução sistemática das imagens dos quadrinhos até seus mínimos elementos, e do Groupe $\mu$ (Cf. GROUPE $\mu .1992$.), que defendem uma teoria que parte de uma descrição densa e sistemática das imagens componentes nos quadrinhos para a sua compreensão (GROENSTEEN, 2015, p. 11-12). Esses modelos semióticos foram construídos para o estudo da imagem, com preocupações também em abranger a arte sequencial, tornando-os referenciais positivos no estudo de histórias em quadrinhos, trazendo para a discussão novos elementos a serem analisados.

Um caso digno de menção especial é de Thierry Groensteen, em seu livro $O$ sistema dos quadrinhos. Nele, o autor belga propõe um modelo teórico para o estudo dos quadrinhos, ao qual nomeou de "sistema dos quadrinhos". Aqui, a partir de uma crítica a outros modelos e perspectivas de análise dos quadrinhos, ele estabelece os elementos dessa teoria, que se caracteriza pelo estudo dos elementos estruturais dos quadrinhos a partir de sua articulação. Ou seja, ao invés de uma análise iconográfica densa, ele pretende entender o processo de significação da narrativa sequencial a partir das relações dos elementos estruturais com a imagem e entre si.

Se opondo a outras correntes que consideram os quadrinhos meramente como uma sobreposição sequencial de imagem e texto, Groensteen considera que, nas histórias em quadrinhos, há a preeminência da imagem sobre o texto, e que essa predominância deve ser ativamente considerada na análise de quadrinhos. É possível uma arte sequencial com imagem, mas sem texto. Porém, o oposto não, dada a dependência existente no gênero do elemento imagético. Mas, ao mesmo tempo, um estudo centrado apenas na análise iconográfica, na visão dele, ainda perderia a compreensão da dinâmica existente da articulação dos elementos iconográficos com os elementos estruturais dos quadrinhos (como o requadro e a calha).

Dessa forma, o sistema dos quadrinhos de Groensteen, apesar de complexo, se desdobra em um modelo semiótico bastante pertinente para a compreensão do suporte material das histórias em quadrinhos, questão bastante ausente em muitas pesquisas que as utilizam como fonte. 


\section{PARTE 3 \\ PROPOSTAS DE ANÁLISES SEMIÓTICAS DOS QUADRINHOS APLICADAS À HISTORIOGRAFIA}

A partir dessas perspectivas, cabe aqui relembrar que a preocupação inicial desse artigo não é propor uma análise semiótica dos quadrinhos, mas de discutir como aprofundar uma análise historiográfica a partir desses referenciais, e de como utilizá-los para enriquecer um trabalho historiográfico a partir desses referenciais teóricos. Essa terceira parte vai se preocupar mais detidamente nesse aspecto, enquanto aponta alguns trabalhos que conciliam usos da semiótica com trabalhos de cunho historiográficos.

\section{A QUESTÃO DO “TEMPO” E O MÉTODO HISTÓRICO}

O primeiro ponto que se deve ter em mente é que, dentro das ciências humanas, o que distingue a ciência histórica das demais é a sua abordagem do tempo. Mais especificamente, a história se distingue, por exemplo, da sociologia e da antropologia pela abordagem diacrônica do tempo (PROST, 2008, p. 95). O historiador, para além de métodos ou teorias, se distingue pela preocupação com os processos sofridos pelo seu objeto diante da ação do tempo, sendo essa dimensão do seu campo de trabalho, por definição.

Dito isso, é inevitável questionar-se se, sendo a dimensão diacrônica do tempo o campo definidor do trabalho do historiador, haveria algum método próprio do trabalho historiográfico. Nessa linha, Antoine Prost problematiza essa questão em seu Doze questões sobre a história, considerando que a história não teria um método que lhe fosse próprio, a não ser o método crítico (PROST, 2008, p. 53-54). E, desprovida de métodos próprios, ela faria apropriações de teorias e métodos de outras ciências, em especial das sociais, incorporando esses referenciais em suas pesquisas e abordagens.

Dessa forma, percebe-se a multiplicidade de possibilidades teóricas e metodológicas para o tratamento historiográfico dos quadrinhos. E a escolha da teoria e do método, bem como das técnicas a serem empregadas, diferiria conforme diferissem os problemas levantados pela e para a pesquisa.

Dentro dessa perspectiva, uma metodologia alicerçada em referenciais semióticos, compreendendo a arte sequencial como uma codificação própria, passível de uma análise semiótica, trás consigo uma série de técnicas potencialmente aplicáveis na obtenção dos 
dados para a pesquisa (ARÓSTEGUI, 2006, p. 400), tendo na maior parte das vezes um caráter qualitativo em vez de quantitativo (ARÓSTEGUI, 2006, p. 400). Dentre elas, ferramentas para a compreensão de elementos estruturais, iconográficos, narrativos dos quadrinhos, mas também os elementos ideológicos.

\section{HISTÓRIA SOCIAL}

Ao mesmo tempo, é importante compreender o contexto da produção do quadrinho como algo historicamente determinado, e não uma produção "atemporal", que existiria independente de um contexto sócio-histórico. Seus autores, bem como o público leitor, pertencem a um determinado meio social, do qual os quadrinhos são, essencialmente, um vestígio, carregando consigo uma carga de experiências comuns, identidades e, principalmente, ideologias desse meio social. E, trazendo essa carga ideológica como vestígio do meio que o produziu, é possível ao historiador utilizá-las para, a partir dele, "fazer a síntese do acontecimento com a estrutura" (PROST, 2008).

Dentro da chamada História Social, a preocupação central está nas estruturas que organizam a sociedade. Procura compreender as conjunturas, as relações entre os elementos componentes dessa sociedade, sejam indivíduos, classes, instituições, ou outros, de forma a compreender o acontecimento, muitas vezes, como expressões dessas conjunturas. E, enquanto produto de consumo de uma sociedade de massas, produzido em escala industrial, os quadrinhos representam em si mesmos elementos para compreender aspectos dessa sociedade. E, nessa perspectiva, dois trabalhos serão apresentados, articulando semiótica no trabalho com os quadrinhos como fonte, estabelecendo uma discussão relevante para o estudo da História Social.

\section{UMBERTO ECO}

O primeiro trabalho citado é o livro Apocalípticos \& Integrados, do italiano Umberto Eco (1993). Publicado originalmente em 1964, ele consiste em uma série de ensaios em que é abordada a cultura de massa e a indústria cultural a partir de recortes diversos. O autor utiliza objetos como os Kitsch (objetos “de mau gosto”), quadrinhos, música, rádio, televisão, para abordar os elementos dessa cultura de massa, discutindo sobre a produção e difusão dessa Fronteiras: Revista de História | Dourados, MS | v. 20 | n. 36 | p. 122-136 | Jul. / Dez. 2018 
cultura, a formação e a veiculação ideológica feita por esses objetos.

Nesse livro, três capítulos são destinados aos quadrinhos como objeto de análise. Nos capítulos sobre o personagem Superman (“O Mito de Superman”) e sobre o personagem Minduim (“O Mundo de Minduim”), Umberto Eco discute, respectivamente, sobre a construção da figura e do mito do Superman, e sobre a constituição e caracterização do microcosmo das tirinhas do Minduim ("Peanuts", no original). Nessas discussões, ele problematiza os referenciais ideológicos veiculados por essas obras, contextualizando-os sócio-historicamente.

Já o terceiro ensaio sobre quadrinhos (que, na verdade, antecede os outros dois na estrutura do livro), e mais relevante para essa discussão, é o capítulo acerca do quadrinho “Steve Canyon", de 1947. Nesse capítulo em questão ("Leitura de 'Steve Canyon'“), Eco analisa minuciosamente a primeira página da tirinha (essa tirinha, lançada originalmente em um jornal, publicava uma página por vez). Nesse estudo, feito quadro a quadro, os elementos iconográficos são analisados de forma detalhada, a partir de onde o autor tenta apreender a construção ideológica que permearia o quadrinho e seria difundida por ele. Problematiza também questões materiais relativas à produção quadrinesca, bem como a editoração e vendagem dos quadrinhos em questão.

Seus referenciais semióticos, bem como as discussões referentes aos quadrinhos dentro de um determinado contexto sócio-histórico, tornam esse livro, e não apenas os capítulos em questão, uma leitura relevante para essa abordagem com relação aos quadrinhos.

\section{MOACY CIRNE}

O segundo trabalho é o livro de Moacy Cirne, A explosão criativa dos quadrinhos (1972), lançado em sua primeira edição de 1970. Nesse livro, o autor, conhecido por publicar inúmeros trabalhos analisando os quadrinhos sob uma perspectiva materialista-histórica, problematiza a importância deles e de seu estudo, abordando uma gama bastante variada de temáticas, indo das análises de elementos estruturais (como os balões e a voltagem onomatopaica) às expressões quadrinescas (como o que ele considerou a tradição literária e a expressão barroca), passando por questões sócio-históricas relacionadas aos quadrinhos, problematizando, por exemplo, a existência de vanguardas artísticas nos quadrinhos e sua historicização. 
Faz também uma análise bastante relevante da história "O Rapto de Nardraka" do mágico herói Mandrake (lançada aqui no Brasil em 1969), onde, a partir de uma extensa decupagem, ele coletou dados o suficiente para compreender como ocorria a representação do tempo na sequenciação dos quadrinhos, estudando os cortes na continuidade narrativa, ao mesmo tempo em que reúne dados estruturais (número de balões, quadros, planos justapostos, etc) suficientes para que outras discussões pudessem ser problematizadas com mais atenção, sendo um modelo relevante de decupagem para quadrinhos.

\section{CONSIDERAÇÕES FINAIS}

Por fim, deve-se ressaltar a relevância dessa discussão teórico-metodológica em torno da semiótica e a história como maneira de permitir aprofundar as análises historiográficas dos quadrinhos. Ressalta-se também a necessidade de uma preocupação com as especificidades desse tipo de fonte, bem como um constante diálogo interdisciplinar para o trabalho com ela. E que o uso da semiótica, bem como as técnicas relacionadas, trás a possibilidade de diferentes desdobramentos analíticos, que aprimorariam os estudos feitos acerca dos quadrinhos, permitindo uma maior profundidade em alguns de seus resultados, desde que respeitadas as questões feitas às fontes e/ou ao objeto de estudo.

\section{REFERÊNCIAS}

ARÓSTEGUI, Julio. Métodos e técnicas na pesquisa histórica. In: A pesquisa histórica: teoria e método. Bauru/SP: Edusc, 2006, p. 513-558.

BRAGA JR., Amaro Xavier, e PERRUSI, Artur. Representações da loucura e da vilania em Batman. In: $9^{a}$ Arte. São Paulo, vol.2, n.1, 33-44, 1o.semestre/2013.

BARI, Valéria. Leitura Escolar e Histórias em Quadrinhos: fruição intelectual, criatividade e formação de gostos de leitores. In: In: $9^{a}$ Arte. São Paulo, vol. 1, n. 2, 51-56, 20. semestre/2012.

BITAZI, Fernanda Isabel. Adaptação em quadrinhos e sua autonomia em relação ao discurso literário. In: $9^{a}$ Arte. São Paulo, vol. 5, n. 1, $1^{\circ}$ semestre/2016.

CIRNE, Moacy. Para ler os quadrinhos: da narrativa cinematográfica à narrativa quadrinizada. $2^{\mathrm{a}}$ Ed. Petrópolis: Editora Vozes, 1975. 
CIRNE, Moacy. A Explosão criativa dos quadrinhos. $3^{\mathrm{a}}$ Ed. Revista. Petrópolis: Editora Vozes, 1972.

CIRNE, Moacy. A Linguagem dos quadrinhos: o universo estrutural de Ziraldo e Maurício de Souza. $3^{\text {a}} E d$, Revista e Ampliada. Petrópolis: Editora Vozes, 1973.

CHINEN Nobu. A construção do preconceito na representação dos negros nos quadrinhos. In: $9^{a}$ Arte. São Paulo, vol.2, n.2, 74-90, 2o.semestre/2013.

DUBY, Georges. História social e a ideologia das sociedades. In: LE GOFF, Jacques, e NORA. Pierre. História: Novos Problemas. Tradução de Theo Santiago. Rio de Janeiro: F. Alves, 1976.

ECO, Umberto. Apocalípticos e integrados. São Paulo: Perspectiva, 1993.

EISNER, Will. Quadrinhos e Arte Sequencial. Tradução Luís Carlos Borges. São Paulo: Martins Fontes, 1989.

EISNER, Will. Quadrinhos e Arte Sequencial: princípios e práticas do lendário cartunista. Tradução Luís Carlos Borges e Alexandre Boide. $4^{\mathrm{a}}$ ed. São Paulo: WMF Martins Fontes, 2010.

GAUTHIER, Guy. Vingt leçons sur l'image et le sens. Paris: Edilig, Mediatèque, 1982.

GIMENEZ MENDO, Anselmo. História em quadrinhos: impresso vs. Web. São Paulo: Editora UNESP, 2008.

GROUPE $\mu$. Traité du signe visuel. Pour une rhétorique de l'image. Paris: Le Seuil, "La Couleur des Idées", 1992.

GUERRA, Fábio Vieira. Super-Heróis Marvel e os conflitos sociais e políticos nos EUA (1961-1981). Dissertação. Niterói: UFF, 2011.

GUERRA, Fábio Vieira. A crônica dos quadrinhos: Marvel Comics e a História Recente dos EUA (1980-2015). Tese. Niterói: UFF, 2015.

GOIDANICH, Hiron Cardoso; KLEINERT, André. Enciclopédia dos Quadrinhos. Porto Alegre: L\&PM, 2011.

GONÇALVES, Alan Ramos. A metáfora em X-Men. São Paulo: USP. Trabalho apresentado no XI Congresso Internacional da ABRALIC: Tessituras, Interações, Convergência, 13 a 17 de julho de 2008 .

GROENSTEEN, Thierry. O sistema dos quadrinhos. Trad. de Érico Assis. $1^{\mathrm{a}}$ ed. Nova Iguaçu: Marsupial Editora, 2015.

SIQUEIRA, Ivan. Hq \& Literatura - FUNDAMENTOS MITOLÓGICOS E FILOSÓFICOS. 
In: $9^{a}$ Arte. São Paulo, vol. 1, n. 2, 51-56, $2^{\circ}$ semestre/2012.

JARCEM, René Gomes Rodrigues. História das histórias em quadrinhos. In: História, imagem e narrativas, $\mathrm{n}^{\circ}$ 5, ano 3, setembro de 2007.

MENDONÇA, Márcio José, e REIS, Luis Carlos Tosta dos. Percepção do Espaço Geográfico nos Quadrinhos. In: $9^{a}$ Arte. São Paulo, vol. 5, n. 2, $2^{\circ}$ semestre/2016.

PROST, Antoine. Doze lições sobre a história. Belo Horizonte: Autêntica Editora, 2008. 